\title{
A Pilot With Electrical Pain in the Face
}

\author{
LT John M. Curnes, MD, MC, USN
}

\section{An intracranial epidermoid cyst is an unusual but treatable cause of trigeminal neuralgia.}

A 25-year-old male student pilot presented to his flight surgeon in Corpus Christi, Texas, with a 1 -year history of episodic left-sided facial pain. He described the pain as electric-like with subsequent tingling sensation. These symptoms were always located on the left side of his tongue and lower lip. They were provoked by chewing, touching, or brushing his teeth. The most recent episode had lasted for 3 days before resolving. He noted 2 similar episodes a few months earlier that he related to periods of high stress.

On physical examination, the student pilot was well appearing with unremarkable vital signs. There were no skin lesions of the head or neck region. His tongue was midline without cutaneous lesions or atrophy. There was no facial numbness or weakness of the mastication muscles. There were no oropharyngeal mucosal or anatomic abnormalities. He had no lymphadenopathy. The remainder of the physical examination was unremarkable. He was seen by both dental medicine and oral surgery providers who did not identify an underlying cause for his symptoms.

When symptoms recurred a fourth time, the student was referred for a magnetic resonance imaging (MRI) of the brain with and without contrast. The MRI demonstrated a left-sided extra-axial mass, involving the cerebellopontine angle (CPA), with imaging features most consistent with an epidermoid cyst (Figures 1, 2, and 3). An audiogram performed at the time of diagnosis revealed no sensorineural hearing loss.

\section{DISCUSSION}

Epidermoid cysts are extra-axial tumors that are benign and slow growing. They constitute about $1 \%$ of all intracranial tumors. ${ }^{1}$ They most commonly occur at the CPA but can also arise in the fourth ventricle and suprasellar regions. ${ }^{2}$ Epidermoid cysts constitute about 5 to $7 \%$ of all CPA tumors. ${ }^{3,4}$ The 2 most common presenting symptoms of these tumors are headache and cranial nerve dysfunction. ${ }^{1}$ Other presenting symptoms may include ataxia, hemiparesis, and tinnitus.

On computed tomography (CT), epidermoid cysts can be identical in density to cerebrospinal fluid, making early detection difficult. On MRI, the lesion is easily seen on diffusion-weighted imaging, due to hyperintensity and restricted diffusion. The cysts rarely enhance, unlike the more common tumors in this region, vestibular schwannomas and meningiomas. ${ }^{5}$

Total neurosurgical resection of the epidermoid cyst is the optimal treatment and is possible in most cases. ${ }^{6}$ Management of these cysts may prove difficult because of their close proximity to the cranial nerves and brain stem. A near-total excision may be necessary for those tumors that have strong adhesions to neurovascular structures. ${ }^{7}$ Literature reports that recurrence after surgery is rare in cases of subtotal removal. ${ }^{8,9}$ Reported postoperative complications may include aseptic meningitis and cranial nerve dysfunction. ${ }^{10}$

\section{Management}

The patient was informed of the presumed diagnosis of brain epidermoid cyst and sent for neurosurgery evaluation. Surgery was indicated and via a retrosigmoid craniotomy, the tumor was removed in total with no complications. On 3-month postoperative follow-up, MRI showed no evidence of residual epidermoid (Figure 4). On physical examination at the follow-up, he was alert and oriented. His surgical incision was well healed. He was neurologically intact with a normal gait. He was released without restrictions from neurosurgical care.

The patient wished to continue flying after successful resection of his cyst. The
John Curnes is the Senior Naval Flight Surgeon at Training Air Wing Four at Naval Air Station Corpus Christi in Texas. Correspondence: John Curnes (john.m.curnes.mil@mail.mil)

Fed Pract. 2021;38(7). Published online July 11. doi:10.12788/fp.0149 
FIGURE 1 Axial Diffusion-Weighted Image

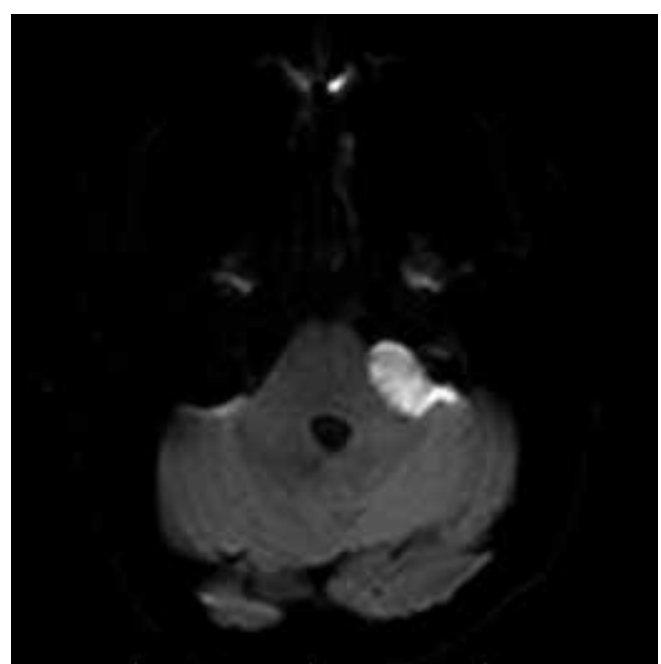

A left cerebellopontine angle lesion can be seen with restricted diffusion, a characteristic imaging finding of epidermoid tumors.

\section{FIGURE 3 Axial T1 Weighted Image} After Gadolinium Administration

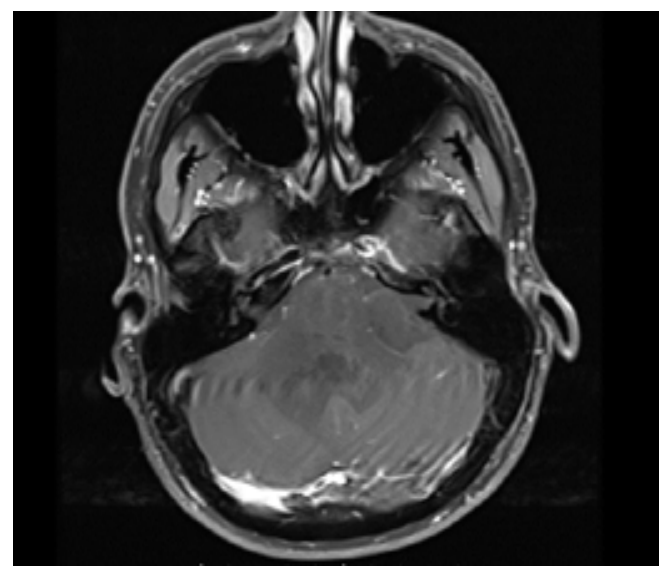

No enhancement can be seen, reflecting the hypovascular nature of epidermoid tumors.

neurosurgical procedure for removal of the epidermoid cyst medically disqualified him for military aviation. ${ }^{11}$ As the patient had no neurologic deficits, a waiver was submitted on his behalf to the Naval Aerospace Medical Institute. The waiver was granted for flying duties, and the patient returned to training. He has had no return of symptoms to date.

\section{CONCLUSIONS}

An intracranial epidermoid cyst is an unusual but treatable cause of trigeminal neuralgia.
FIGURE 2 Axial T2 Weighted Magnetic Resonance Image

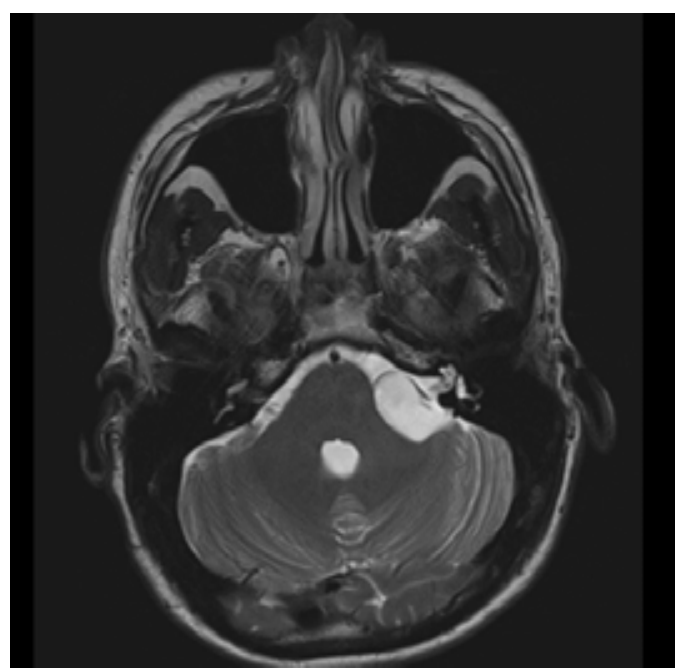

High T2 signal demonstrated in the lesion and confirmed its extra-axial location, that is, not arising from the brain stem.

\section{FIGURE 4 Axial T2 Weighted Image, Postresection}

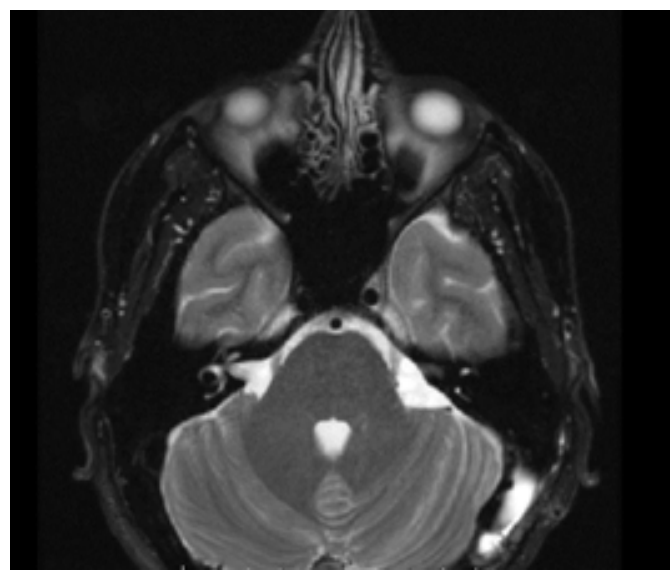

Return of the normal contour of the brain stem and normal course of the left trigeminal nerve following tumor removal can be seen.

Gross total removal, without cranial nerve or cerebellar deficits, resulted in the patient's complete return to health and training as a pilot.

\section{Author disclosures}

The author reports no actual or potential conflicts of interest with regard to this article.

\section{Disclaimer}

The opinions expressed herein are those of the author and does not necessarily reflect those of Federal Practitioner, Frontline Medical Communications Inc., the US Government, or any of its agencies. 


\section{References}

1. Farhoud A, Khedr W, Aboul-Enein H. Surgical resection of cerebellopontine epidermoid cysts: limitations and outcome. J Neurol Surg B Skull Base. 2018;79(2):167-172. doi:10.1055/s-0037-1606220

2. Hung LC, Wu CS, Lin CC, Fang WK, Hsu YC. Epidermoid cyst presenting as isolated trigeminal neuralgia - two case reports. Acta Neurol Taiwan. 2013;22(3):133-137.

3. Feng R, Gu X, Hu J, et al. Surgical treatment and radiotherapy of epidermoid cyst with malignant transformation in cerebellopontine angle. Int J Clin Exp Med. 2014;7(1):312-315.

4. Friedmann DR, Grobelny B, Golfinos JG, Roland JT. Nonschwannoma tumors of the cerebellopontine angle. Otolaryngol Clin North Am. 2015;48(3):461-475. doi:10.1016/j.ote.2015.02.006

5. CPA-IAC In: Harnsberger HR, Glastonbury CM, Michel MA, Koch BL Branstetter BF IV. Diagnostic Imaging: Head and Neck, 2nd ed. Amirsys, Inc; 2011:VI(8):6-9

6. Hasegawa M, Nouri M, Nagahisa S, et al. Cerebellopontine angle epidermoid cysts: clinical presentations and surgical outcome. Neurosurg Rev. 2016;39(2):259-267. doi:10.1007/s10143-015-0684-5

7. Safavi-Abbasi S, Di Rocco F, Bambakidis N, et al. Has management of epidermoid tumors of the cerebellopontine angle improved? A surgical synopsis of the past and present. Skull Base. 2008;18(2):85-98. doi:10.1055/s-2007-991108

8. Son DW, Choi $\mathrm{CH}$, Cha SH. Epidermoid tumors in the cerebellopontine angle presenting with trigeminal neuralgia. J Korean Neurosurg Soc. 2010;47(4):271-277. doi:10.3340/jkns.2010.47.4.271

9. Schiefer TK, Link MJ. Epidermoids of the cerebellopontine angle: a 20-year experience. Surg Neurol. 2008;70(6):584590; discussion 590. doi:10.1016/j.surneu.2007.12.021

10. Meng L, Yuguang L, Feng L, Wandong S, Shugan $Z$, Chengyuan W. Cerebellopontine angle epidermoids presenting with trigeminal neuralgia. J Clin Neurosci. 2005;12(7):784-786. doi:10.1016/j.jocn.2004.09.023

11. Naval Aerospace Medical Institute. US Navy Aeromedical reference and waiver guide. Updated March 31, 2021. Accessed June 17, 2021. https://www.med.navy.mil/sites /nmotc/nami/arwg/Documents/WaiverGuide/Complete _Waiver_Guide.pdf 